\title{
Students and Faculty Perception on Integrated Teaching in MBBS Phase I
}

\author{
M. Kalpana \\ Associate Professor, Department of Physiology, All India Institute of Medical Sciences, Bibinagar, Telangana
}

\begin{abstract}
Introduction: The knowledge learnt in isolation is rapidly forgotten. The syllabus which is taught to students appears like different blocks and unable them to integrate and correlate the knowledge. The present scenario creates disinterest among the students and as a result the art and practice of medicine is not grasped as a whole. One of the method to remove the hurdle is by integrated teaching. This type of teaching allows the student to develop the skills in investigation, analysis and also to perceive the patient as a whole. It acts as a bridge for connecting knowledge and practices.
\end{abstract}

Objectives: To assess the students and faculty perception on Integrated teaching and to assess the effectiveness of integrated teaching.

Method and Materials: The study was conducted in first year MBBS students of 2017. The integrated teaching was planned for two main topics. The 150 students and 20 faculty perception was taken through prevalidated questionnaire. The effect of integrated teaching on the performance of the students was assessed through pre- test and post- test and statistical analysis was done using paired ' $t$ ' test.

Results: Majority of the students accepted that the integrated teaching method was interesting and interactive (48.6\%). 55\% of the faculty were comfortable and satisfied with this method. The mean values of the post and pre- test were statistically significant (mean $\pm \mathrm{SD}, 7.57 \pm 0.958)$ and $(5.72 \pm 0.684)$ respectively.

Conclusion: Integrated Teaching sessions were well-appreciated by students and faculties. To improve the critical reasonings kills and self-directed learning of students, integrated teaching should be implemented in the curriculum.

Keywords: Integrated teaching, perception, faculty.

\section{Introduction}

The knowledge learnt in isolation is rapidly forgotten . Basic science courses are typically taught as standalone, independent content domains in most of the medical colleges in India and there is negligible opportunity for interlinking of concepts learned in one discipline with the other. Thus the lack of integration in current curriculum models leads to poor conceptual understanding. ${ }^{1}$ The syllabus which is taught to students appears like different blocks and unable them to integrate and correlate the knowledge. The present scenario creates disinterest among the students and as a result the art and practice of medicine is not grasped as a whole. ${ }^{2}$ One of the method to remove the hurdle is by integrated teaching. Integration is defined as organization of teaching matter to interrelate or unify subjects frequently taught in separate academic courses or department ${ }^{3}$. This type of teaching allows the student to develop the skills in investigation, analysis and also to perceive the patient as a whole. ${ }^{4}$ Regulation on undergraduate medical education 1997, gives more importance for encouraging integrated teaching by using a problem based learning appoarch. ${ }^{5}$ Integrated teaching acts as a bridge for connecting knowledge and practices. There is more stress on need based curriculum. The integrated teaching will help to explore and understand problems and develop new solutions. ${ }^{6}$ The main aim of the study was to asses the students and faculty perception 
on Integrated teaching and to assess the effectiveness of integrated teaching.

\section{Materials and Methodology}

After taking ethical committee clearance and consent from faculty and students, the study was conducted in first year MBBS students, 2017 batch at Kamineni Academy of Medical Sciences and Research Center, L. B nagar, Telangana. The batch consists of 150 students. It is a cross sectional study. With the permission of the Head of Department of Physiology, Anatomy and Biochemistry, the integrated teaching was planned for two main topics (Jaundice and Coronary circulation). One topic was conducted in one month and the other topic in the next month. The 150 students and
20 faculty perception was taken through pre-validated questionnaire. The effect of integrated teaching on the performance of the students was assessed through pre test and post test and statistical analysis was done using paired ' $\mathrm{t}$ ' test.

Results-Out of 150 students, 144 students were present and 6 were absent. Majority of the students accepted that the integrated teaching method was interesting and interactive (48.6\%)(Fig 1). 55\% of the faculty were comfortable and satisfied with this method. (Fig 2). The mean values of the post and pre test were statistically significant (mean $\pm \mathrm{SD}, 7.57 \pm 0.958$ ) and $(5.72 \pm 0.684)$ respectively. (Table -1$)$.

Table 1: Comparison of Pre and Post test marks (Total marks=10)

\begin{tabular}{|l|c|c|c|c|}
\hline Marks & Mean & SD & "t” value & P value \\
\hline Pre test & 5.72 & 0.684 & \multirow{2}{*}{0.00} \\
\hline Post test & 7.57 & 0.958 & & 0.79 \\
\hline
\end{tabular}

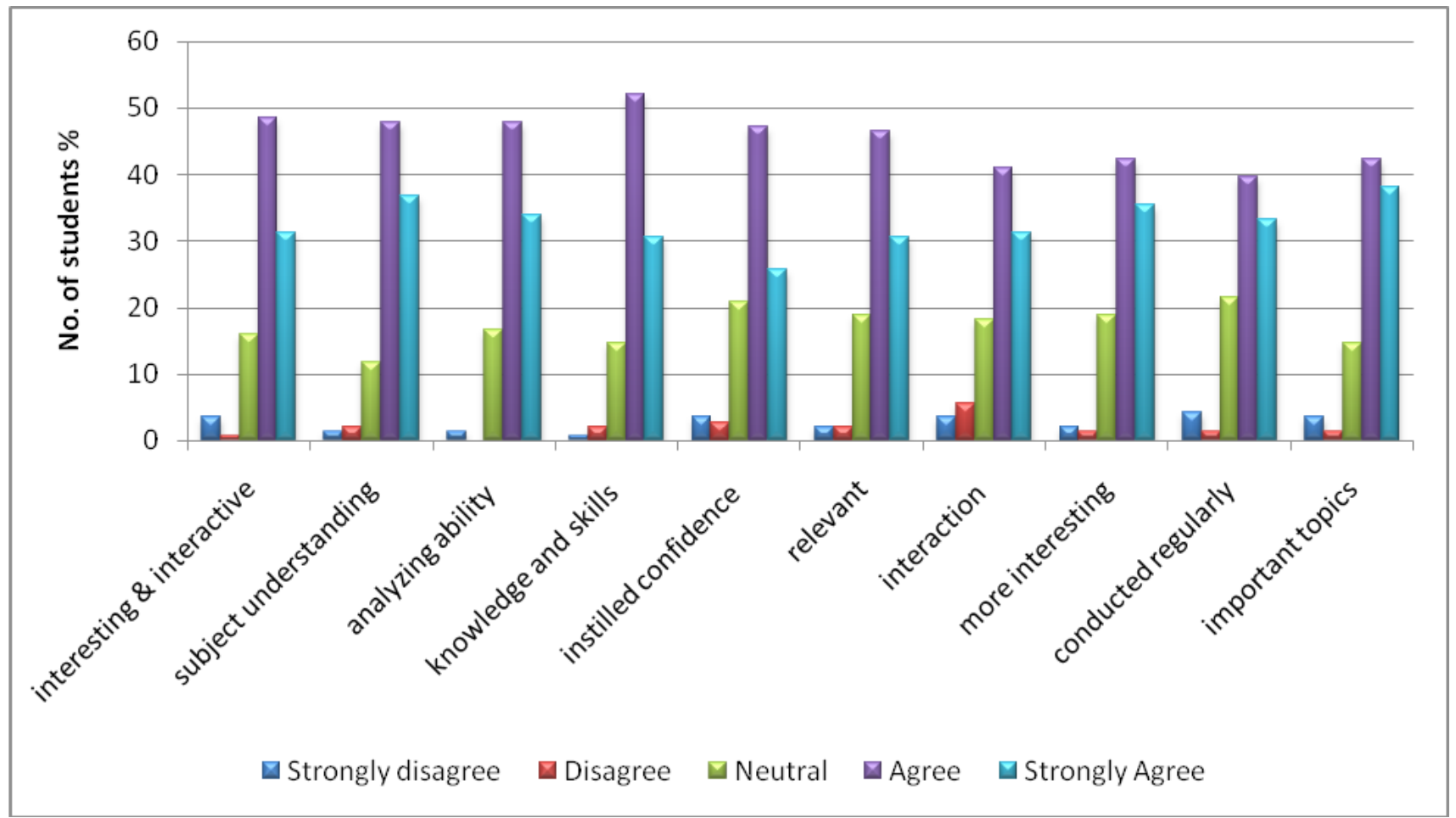

Figure 1: Perceptions of students on Integrated teaching as \% responses on 5 point Likert scale (n=144). 


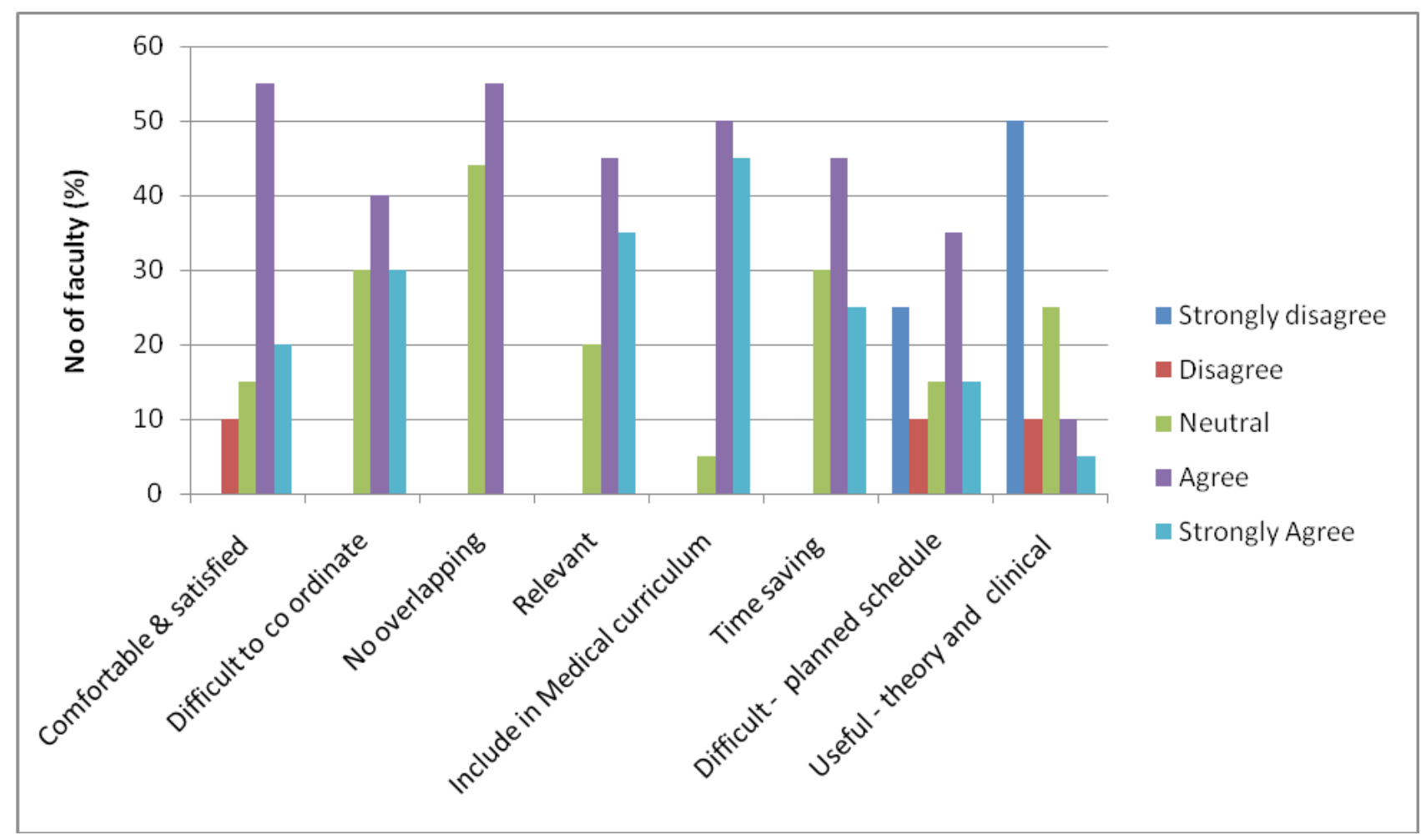

Figure 2: Perceptions of faculty on Integrated teaching as \% responses on 5 point Likert scale (n=20)

\section{Few suggestions by the students were:}

1. Should distribute notes on the related topics.

2. Black boards and chalk can be used.

3. PPT to be shared with students.

4. Should not be extended for a long time.

5. Assessment can be conducted in between.

6. More classes should be taken by this method.

7. All lectures should be integrated.

8. Not to conduct these sessions during post lunch.

\section{Comments from the teachers were:}

1. Case Demonstration can't be done during these sessions.

2. It is Time taking to prepare time table and plan of execution of classes.

3. Difficult to introduce during normal planned schedule.

\section{Discussion}

$48.6 \%$ of the students accepted that the integrated teaching method was interesting and interactive. $30.6 \%$ of the students were interested to conduct these sessions regularly. S. Joglekar found that integrated approach improved students' understanding, removed topic phobia, developed interest in the topic. ${ }^{7}$

$\mathrm{He}$ also revealed the following advantages of integration: 1. Integrated teaching reduces the fragmentation medical courses. 2. It prevents repetition and waste of time. 3. Students learn to apply their knowledge to clinical practice. 4. Promotes interdepartmental collaboration. 5. Rationalization of teaching resources .Similar findings were observed in study done by Basu $\mathrm{M}$ et al where they found that overall rating by students about integrated teaching was very good new method. ${ }^{8}$

Few students found integrated teaching to be boring. Similar findings were found by Madhuri Kate ${ }^{4}$. In her study the students gave a feedback that Preclinical subjects were boring because they are theoretical and taught in a fragmented manner

$55 \%$ of the faculty were comfortable and satisfied with this method. $45 \%$ of the faculty preferred that, this method was time saving. Similar findings were observed by Neelam Anupama Toppo ${ }^{3}$. In our study 
$47.9 \%$ students had an increase in the analyzing ability. Similar findings were seen by Schmidt $\mathrm{HG}^{9}$. Students trained with integrated curriculum were more accurate in diagnosis of the clinical disorders than those trained in a conventional curriculum. Another study done in 2013 revealed that the students were enthusiastic, have improved cognitive domains by the new teaching learning method and were benefitted by the integrated teaching ${ }^{10 .}$

The mean values of the post and pre test were statistically significant (mean $\pm \mathrm{SD}, 7.57 \pm 0.958$ ) and (5.72 \pm 0.684 .) respectively. Similar studies were done at Seth GS Medical College, Mumbai and they revealed that the marks obtained by the students who had undergone integrated teaching was statistically significantly greater than those who did not. ${ }^{4} \mathrm{~A}$ change from conventional classroom teaching to newer method which encourage interactive learning through active participation. It is well known that students learn more when involved actively in learning than when they are passive recipients of instructions ${ }^{11}$.

\section{Conclusion}

Integrated Teaching sessions were well-appreciated by students and faculties. To improve the critical reasoning skills and self-directed learning of students, integrated teaching should be implemented in the curriculum.

\section{Source of Funding: Self}

Conflicts of Interest: There are no conflicts of interest.

Acknowledgement: I thank Faculty and studentsof KAMSRC, LB NAGAR, TELANGANA for actively participating in this study .I also thank Dr Sunil Pal Singh, Associate Professor, Department of Community Medicine, for his guidance for statistical analysis.

\section{References}

1. Harden RM. The integration ladder: A tool for curriculum planning and evaluation. Med Educ. 2000;34:551-7.
2. Doraisamy R, Radhakrishnan S. The effectiveness of integrated teaching over traditional teaching among first year MBBS students: a preliminary study. Med J DY Patil Univ 2013; 6(2):139-41.

3. Toppo NA, Lazarus M, Seth RJ et al. Introduction of Integrated Teaching learning module in second M.B.B.S curriculum. International Journal of Contemporary Medical Research 2016; 3(5):1275-79.

4. Kate MS, Kulkarni UJ, Supe A, Deshmukh YA. Introducing integrated teaching in undergraduate medical curriculum .International Journal of Pharma Sciences and Research 2010;1:18-22.

5. Kumar KM, Mysorekar VV, Raja S. Student's perception about integrated teaching in undergraduate medical curriculum. Journal of Clinical and Diagnostic research 2011;5(6):125659.

6. Kadirvelu A, Gurtu S. Integrated learning in medical education: Are our students ready? Medical Science Educator 2015;25:549-51

7. S Joglekar, PS Bhuiyan, S kishore 1994. Integrated teaching-Our Experience. Journal of Postgraduate Medicine.;40:231-2

8. Basu M, Das P, Chowdhyru G. Introducing integrated teaching and comparison with traditional teaching in undergraduate medical curriculum :A pilot study. Med J of Dr .D .Y Patil Vidyapeeth 2015;8(4):431-438

9. Schmidt HG, Machiels-Bongaerts M, Hermans H, ten cate TJ Venekamp R, Boshuizen HP.1996. The development of diagnostic competence : Comparison of a problem based, an integrated and a conventional medical curriculum. Acad Med 71:658-64.

10. Neena Nagdeo, Tanuja Manohar, Anjali Kawthalkar, Mohan Joshi 2013. Innovative Integrated Teaching for MBBS Undrergraduates. South East Asian Journal Of Medical Education., Vol 7, no.2,49-50

11. Ronald M Harden 2000, Curriculum. Medical Education . Blackwell Science Ltd. 34:551-557. 